\title{
An Analysis of the Behavior Logic of the Spread of Christian Religion on the Internet
}

\author{
Bijun $\mathrm{Wu}^{1, *}$, Xiaowei Liang ${ }^{2}$ \\ ${ }^{1}$ School of Ethnology and Sociology of Southwest Minzu University, Chengdu Sichuan, China \\ ${ }^{2}$ School of public management of Southwest Minzu University, Chengdu Sichuan, China \\ *Corresponding author. Email: cooly1975@163.com
}

\begin{abstract}
When the network emerged and provided a "field" for religious organizations and individual believers that might exceed the scope of traditional public affairs management, the expression norms of individual believers in the "public field" space of the network and the balance between "private religious beliefs" and traditional "public religious beliefs" were broken. Through empirical research, it is found that the online religious communication behavior of Christian believers has changed the structure and function of traditional religious organizations. The use of Internet will lead to structural differentiation within religious organizations, which is manifested not only among clergy but also in the governance structure of the organization. On the other hand, the use of the Internet will cause the related activities of religious organizations to overflow the physical space of religious sites. The change in the relationship between activities and sites will inevitably promote or even cause the corresponding changes in the management mode and even rules of religious affairs.
\end{abstract}

Keywords: Christian believers, Network Communication, Structure-Differentiation, De-centralization

\section{INTRODUCTION}

The importance of dissemination to religion determines the importance of the dissemination subject in religion. In addition to religious organizations, believers as the disseminated are also important dissemination subjects. When the Internet emerges and provides religious organizations and individuals with a "field" that may exceed the scope of traditional public affairs management, the difference between the virtual public sphere of this network and the public sphere of social reality, religious organizations and individual believers The expression norms in the online public domain space and the reasonable balance between private religious beliefs and traditional public religious beliefs have become practical questions to be answered by religious online communication.

This research focuses on the online communication of religious believers and aims to examine the logic and social effects of religious believers' use of the Internet for religious communication, as well as the structural adjustments that may be brought about by the communication activities to religions and religious organizations, and their possible occurrences. The problem gives a theoretical analysis of religious sociology and exploration of the path of government religious management practice. The basic judgment of this research is that the online religious communication behaviors of faculty members, groups of believers, and workers who have not converted to their beliefs and who take this as their profession will change the structure and function of traditional religious organizations. On the one hand, Internet use can lead to structural differentiation within religious organizations, which is manifested in both the clergy and the organization's governance structure; on the other hand, Internet use can cause the activities of religious organizations to overflow religious organizations. The physical space of place, changes in the relationship between activities and places, will inevitably promote or urge the corresponding changes in the management methods and rules of religious affairs.

The question to be answered in this topic is, what impact will Internet communication have on religions, religious organizations, and believers' belief expression behavior? What do these influences mean for the management of religious affairs from the perspective of government public management? To answer these two questions, we must make both a relational and spiritual assumption. Therefore, we use a combination of 
quantitative and qualitative method work, including questionnaire surveys, interviews, and observations. Since the population of religious believers is not easy to frame, we finally adopted the typical method of combining conceptual sampling, chance sampling, and snowball sampling to obtain survey subjects. Although we cannot use stratified sampling to obtain samples, we have tried to control the distribution and structure of samples during the survey process, taking gender, age, occupation, education level, and other factors into consideration, and try our best to Both levels can be considered.

Based on the above considerations, we launched the project "Research on the Internet Communication of Religious Organizations and Their Norms". The project survey points are mainly concentrated in Beijing, Nanjing, and Sichuan. Each survey point is divided into Buddhism, Taoism, Christianity, Catholicism, and Islam. Sections to get samples. A total of 540 questionnaires about believers were distributed, including 150 for Buddhism, 120 for Taoism, 150 for Christianity and Catholicism, 120 for Islam, and 503 valid questionnaires, including 150 valid questionnaires for Buddhism, 102 for Taoism, and Christianity. A total of 149 from Catholicism and 102 from Islam. A total of 100 questionnaires for religious organizations were distributed, of which 50 were from their own portal and 50 were not from their own portal. Besides, in-depth interviews with believers and clergy were conducted in each section of each survey site, and a total of 70 interviews were obtained, including 21 for Buddhism, 10 for Taoism, 16 for Christianity and Catholicism, and 23 for Islam. This article mainly analyzes the data of Christianity (including Christianity and Catholicism).

Compared with other religions, the rise and development of Christianity's online spread are consistent with its doctrines, which may be related to the large difference between the missionary power granted by the religion itself and other religions. For example, there is a sentence in the Bible that requires its followers to "go out and preach the gospel everywhere." Christian organizations even believe that the job of the church is to spread the gospel as much as possible. Following the "electronic church" in the 1950s, the "virtual church" based on the Internet has become an important way for believers to obtain religious knowledge, achieve group interaction and group identity in the Internet age.

\section{KNOWLEDGE AND INFORMATION ACQUISITION-THE BASIC FORM OF CHRISTIANITY NETWORK COMMUNICATION}

Internet communication has a two-way impact on the construction of religious sacred spaces. On the one hand, the online spread of religion may increase religious identity. The network can provide a huge amount of information. Although it is difficult to verify the accuracy of the information and the reliability of the provider, when the information is presented and accepted, it has gained legitimacy and legitimacy. On the other hand, the dissemination of religion is first of all the dissemination of information, and the dissemination of information inevitably includes questioning and dispelling authority. If the information and its providers-religious organizations, clergy, and believers - are not identified during the process of network dissemination, universal doubts about authority will inevitably arise. But cyberspace is, above all, an information space. In this space, Christians use the Internet to understand religious knowledge, listen to and watch the lectures of priests, and exchange religious materials with fellow practitioners through the Internet. It can be said that the acquisition of religious knowledge and the dissemination of information are the most basic and even the most important manifestation of Christianity's network dissemination.

\subsection{Believers have a relatively high degree of network access to religious knowledge and related information}

The survey shows that Christians use the Internet to obtain religious knowledge to a high degree. The proportion of respondents who understand religious knowledge through the Internet reaches $71.1 \%$ and only $28.9 \%$ of the respondents who "never" learn their religious knowledge through the Internet. We have reason to believe that as the popularity and habituation of Internet use further increases, the proportion and frequency of believers to obtain religious knowledge and related information through the Internet will further increase.

The performance of obtaining religious knowledge and related information through the Internet is diverse. It can be understood through texts and videos on the Internet, and at the same time, they can listen to or watch sermons on the Internet, and consult the clergy of the religion or communicate with the faithful through the Internet, And so on. The data shows that the proportion of respondents who watch or listen to sermons on the Internet "frequently" or "occasionally" has reached $45.6 \%$, which is lower than those who "never" (54.4\%).

Besides, the proportion of respondents who "ask the clergy of their own religion through the Internet" totaled $41.6 \%$, which was lower than the previous two items. This may be due to the different understanding of the connotation and manifestation of religious knowledge by the respondents. At the same time, the first two activities are basically one-way communication, while asking the clergy for advice is an interactive behavior.

Correlation analysis found that the above three types of behaviors are related to varying degrees. Among them, 
the correlation coefficient between "Do you often learn about this religion through the Internet" and "Do you often watch or listen to sermons online" is 0.617 ; The correlation coefficient between "Do you know about this religion on the Internet" and "Do you often consult the clergy of this religion on the Internet" is 0.261 ; The correlation coefficient between "Do you often watch or listen to sermons online" and "Do you often consult the clergy of this religion on the Internet" is 0.347 . The above correlation coefficients are all statistically significant at the significance level of 0.01 . On the one hand, they reflect the consistency of similar behaviors of Internet users, and on the other hand, they also illustrate the validity of the survey results.

Our interview materials also support the above view to a certain extent, that is, most respondents use the Internet more as a means and way to obtain religious information and knowledge. When Client 1 and Client 2 were asked "What are the main aspects of the Internet's help to you in religious beliefs?", they both believed that the Internet is more of a channel or way for them to obtain religious information. In fact, the 16 interview samples we obtained have emphasized this point very consistently.

In a broader sense, news and information related to religion are themselves part of religious knowledge, and Christians' emphasis on news within the church seems more conclusive. At the same time, the magnanimity of online information also tests the ability of believers to discern information, and even the devotion of faith. The interviewee's emphasis on "believe in the Lord" in the use of the Internet may help to understand the potential of the Internet to dissolve the authority of traditional beliefs.

\subsection{Believers are more active in using the Internet to spread religious knowledge}

Research has found that Internet communication has strengthened the interpretation power of Christian believers. In network communication, believers are both the target and the main body of the communication. The popularity of the Internet has to a certain extent strengthened believers' right to interpret the Bible. At the level of religious knowledge and information, as users of believers, their information dissemination behavior and information acceptance behavior are consistent. In this regard, the three indicators for Christians to study the "Bible" through the Internet, recommend studying "Bible" materials, communicate with the faithful, and publish their experience in studying the "Bible" can be examples.

The survey data shows that the proportion of respondents studying the Bible through the Internet to communicate with church members has reached $47.7 \%$. The other two indicators are $43.0 \%$ and $49.7 \%$, respectively, with a small difference. It should be said that the online exchange of materials, publications, and exchanges of learning experiences among believers can trigger each other; moreover, Internet communication based on the spread of religion can also trigger social interactions among believers. In this regard, interview data can provide varying degrees of confirmation.

Client 03: I added the QQ group of the church. I also often see people in the group posting things related to faith, such as scriptures in the "Bible". I think this still has a catalytic effect on faith. For example, if you are tired after working all day, open QQ, and suddenly a "Bible" verse appears in the group, then you will be much calmer at once.

In other words, when believers realize that the behavior has a positive effect on their own social interactions in the process of using the Internet to spread religion, the online and offline interactions between believers and the formation of self-organization on this basis also There is a corresponding necessity. In other words, while the Internet grants believers the right to interpret religious classics, it also promotes the formation of social interactions and belief-based self-organization among believers.

\section{COEXISTENCE OF DIFFERENTIATION AND TRANSITION-THE BASIC CHARACTERISTICS OF CHRISTIAN ONLINE RELIGIOUS ACTIVITIES}

Will the construction of the Christian network space bring about the networking of believers' religious practice? That is to say, will religious rituals follow the continuous construction of the sanctification of cyberspace and transplant religious behaviors that exist in the real world into cyberspace, thereby weakening or strengthening actual religious practices? If this change is happening, will it bring about changes in the relationship between believers and clergy, believers and churches, believers and religious organizations, and believers and believers?

\subsection{Believers have a high degree of participation in online Bible study}

The way that believers learn the Bible through the Internet can be one-way knowledge acquisition, or they can interact with church members through the Internet to exchange experiences or information about studying the Bible. Survey data shows that these two learning methods have a high degree of participation.

Besides, the convenience of the Internet is also one of the reasons why Christians, especially relatively young Christians, tend to use it to study the Bible. The survey shows that a total of $43.6 \%$ of the respondents believe that the Internet can make it easier for the faithful to gather 
together to study the "Bible", and only $16.1 \%$ of the respondents explicitly denied this option.

\subsection{Believers have low participation in online religious ceremonies}

Prayer is one of the important ceremonies of Christianity. The questionnaire survey found that among the 149 respondents, 23 have experience of praying online, accounting for $15.4 \%$ of the sample.

Although the proportion of believers participating in online prayer is relatively low, the process of online prayer from scratch illustrates the variability of believers' cognition and attitude towards online religious practice. This variability also reflects the transitional characteristics of network usage. Based on this, it seems to be inferred that respondents with a positive attitude will be more willing or inclined to practice online religion if conditions permit. Our survey shows that $14.8 \%$ of the respondents believe that the Internet has increased their connection with the church, and $48.3 \%$ of the respondents said they are "unsure". This proportion is basically the same as the respondents who are involved in online prayers.

Undoubtedly, there is a difference between traditional religious communication and Internet communication. The former emphasizes mystery and sacredness, and the physical presence must be based on sensory experience. At present, when the practice of network technology communication is still in the developing stage, it will take some time for religious communication to be realized on the Internet to "spread" the sense of presence. It is foreseeable that with the popularization of VR systems and artificial intelligence, the spread of sacredness and mystery based on the sense of presence will also be realized to a certain extent. Therefore, at the present transitional stage, the presence advantage based on physical space is still irreplaceable in the spread of religion. Of course, the popularization of the mobile Internet has led to the weakening of believers' requirements for on-the-spot experience in religious communication, which will also have a corresponding effect on the advantages of traditional religious communication.

\subsection{Online religious activities of believers have a positive impact on online-like religious behaviors}

Although it is clear that there are relatively few respondents who participate in online prayers, the proportion of religious activities organized by church clergy or believers through the Internet is relatively high. The data shows that $45.70 \%$ of the respondents "frequently" or "occasionally" participate in various activities organized by the church through the Internet. Although the activities organized by the church may not be classified as religious ceremonies, there is no doubt that these leading activities will inevitably include the meaning, value, and even behavioral orientation and mode of Christianity, and to a large extent have the nature of the religious practice.

Further analysis showed that the proportion of respondents who participated in the "various activities organized by the faithful through the Internet" was slightly different from the proportion who participated in the activities organized by the church through the Internet, only $0.6 \%$, and the correlation coefficient reached 0.548 .

Correlation analysis also found that online religious practices have a significant positive impact on similar religious practices, such as helping to print scriptures and participating in charitable activities. Among them, the correlation coefficients of "Have you participated in online prayer" and "Have you participated in helping to print scriptures" and "Have you participated in charity activities" are 0.640 and 0.386 respectively, and both are significant at the significance level of 0.01 .

However, it is worth pointing out that our interview results failed to show the positive impact of online activities on offline activities. For example, in the interview, the case owner 07 had a clear understanding of the vague characteristics of the virtual society of the Internet and adopted a certain skepticism and a spirit of discrimination towards the religious knowledge, information, and the people with whom he communicated on the Internet.

Most of the other cases indicated that they did not or rarely participated in offline activities. In this regard, we believe that a cautious attitude towards the virtual society of the Internet and the spread of religion on the Internet is a manifestation of the rational characteristics of believers and conforms to the rational choice of action in a secular society. However, the way of collecting data may have affected some of our interview results to some extent. In today's China, the sensitization atmosphere formed in the management of religious activities and religious communication will to a large extent affect the authenticity of the data and information we obtain in field investigations. The questionnaire method is anonymous, the respondents are more likely, to be honest, and the data and information obtained are relatively more credible. Interviews mean that at least one witness will know of certain situations that the client believes may belong to sensitive areas. In this situation, the speaking mechanism will naturally activate. We believe that this is also one of the reasons for the partial conflict between the interview data and the questionnaire data results. 


\subsection{The influence of believers' online religious activities on offline religious activities is divergent}

\subsubsection{The influence of believers' online religious practice on actual religious practice is multi- directional}

The influence of Internet religious communication on believers is multifaceted. It can affect the beliefs and attitudes of believers to their religion, and they can also affect the attitudes and cognitions of religious organizations and actual religious sites (churches). The religious behavior or practice of believers includes the religious practice on the Internet as well as the religious practice in the real world.

The substitutability of internet communication in some aspects has changed the attitude of believers towards actual religious participation. According to the survey, a cumulative proportion of $34.9 \%$ of the respondents believes that believers can learn knowledge of their religion without going to church, and $30.9 \%$ of the respondents believe that it does not matter. Only $34.2 \%$ of the respondents believe that even In the Internet age, going to church is also necessary.

Regarding the question of whether believers' involvement in online religious practice will affect their religious participation in real social life, we analyzed the relationship between the respondents' online study of the scriptures and church participation. The results showed that the frequency of going to church was increased by $24.2 \%$ through the use of online learning, 59.1\% thought that there was no change, and $16.8 \%$ thought it had decreased. This also means that the online religious activities of believers have an impact on their willingness to participate in actual religious activities.

First, a cumulative proportion of $40.9 \%$ of the surveyed believes that online learning has changed the number of times they go to church. Second, the influence of online religious activities on actual religious activities is bidirectional. $24.2 \%$ of the surveyed believe that online learning has promoted their behavior to go to church, while $16.8 \%$ of the respondents believe that online learning of the classics has reduced going to church. The number of times. Through correlation analysis, it is found that there is a certain negative correlation between online religious behaviors and offline religious behaviors, with a correlation coefficient of -0.232 ; third, the offline religious activities of most of the respondents are not affected by online religious activities Impact.

\subsubsection{Internet religious activities have a certain substitution and promotion for actual religious activities}

How to understand the multi-dimensional influence of believers' online religious activities on actual religious activities? We think it is related to the following two aspects.

First of all, in terms of the relationship between the virtual space of the network and the real society, the substitution of the sacred space constructed by the spread of religious networks to the real space is obviously not absolute. For now, both have their irreplaceability. For example, religious participation in the physical presence in the real sacred space, the experience brought about and the convenience of religious learning and communication in the virtual space on the Internet can be completely parallel. This is exactly what client 5 said.

Client 05: I think the resources on the Internet are a bit more comprehensive than the information on Christianity in the actual religious sites. The Internet is now relatively strong, and (in reality) the information held by a certain Christian church in a certain place is still relatively (subject to) limitations. The Internet and churches are both helpful to faith in modern society, and the two cannot replace each other.

Secondly, in terms of the relationship between cognitive behavior and practice, the influence of online religious involvement on religious devotion is also multidimensional. The behavior of religious cognition may not only strengthen the believers' cognition and behavior of actual religious participation but also dispel their cognition and behavior of the importance of actual religious participation. As client 8 said.

Client 8: The learning materials on the Internet only provide a convenient and quick way to understand Christianity. But there will also be some extreme ideas on the Internet, which hurt believers and non-believers.

\section{ACTIVE AND PLURALISM IN A PARALLEL-THE INITIATIVE OF CHRISTIAN BELIEVERS IN ONLINE PREACHING AND THE PLURALISM OF INFLUENCING FACTORS}

Propagating the gospel is the basic religious duty of every Christian believer. In other words, the Christian religion can find the basis for its believers to actively spread the religion in the doctrinal, and then make Internet users as believers have a deeper involvement in using the Internet to spread the religion to others. 


\subsection{Believers have a strong initiative to spread the religion to others through the Internet}

Christians have a high degree of recognition of their own position and role in Internet promotion, which will inevitably be reflected in the practice of communication. According to the survey, $37.6 \%$ of the respondents answered that they have spread their religion online. This data far exceeds that of Buddhism and Taoism but is lower than the proportion of respondents who believe in Islam.

The aforementioned respondents' high involvement in online missions and other religious activities in the questionnaire is inconsistent with the low degree of selfreported participation in interviews. The results of the questionnaire analysis are also shown here. Inconsistent contradictions with the interview results.

Client 8: I think non-believers can't believe in a religion based on a network alone. Religion still needs to be face-to-face, true communication, and then through participation in churches and Bible studies. The Internet will only provide a way to query information.

In fact, this shows to a certain extent that a considerable number of believers who spread their religion to others through the Internet have a clearer uncertainty, or even more certainty, about whether the target will be able to accept Christianity based on their own Internet communication. However, a relatively high percentage of believers will use the Internet to preach. The reason seems to be that the communicator does not care about the communication effect, that is, whether the target of the communication accepts Christianity or even converts, but cares about the communication itself. At the doctrinal level, communication means glorifying God and fulfilling religious obligations. Therefore, we can think that the online preaching behavior of Christian believers is more common, and the main reason is the doctrinal significance of the dissemination behavior itself.

\subsection{The influencing factors of believers' online preaching behavior are diverse}

The analysis found that the influencing factors that influence the online missionary behavior of Christian believers are mainly manifested in three aspects.

\subsubsection{The gender and education level of believers are related to their religious online communication behavior}

Data analysis found that the behavior of sharing the experience of the Bible in similar behaviors reflects the characteristics of gender differences, and is weakly correlated with gender, with a correlation coefficient of 0.200 ; there is also a correlation between the religious information dissemination behavior of Christian believers and education level The correlation coefficient is 0.232 . Based on the strong correlation between similar behaviors in the dissemination of religious information by believers, we can even infer that such behaviors are related to the gender and education level of believers. As far as the analysis results are concerned, it is particularly important to emphasize that the assumption that Christianity believers' online religious communication behaviors will show strong age characteristics has not been verified in the relevant analysis results, and the marital status and religious communication behaviors are not. Related.

In fact, this means that as believers of Internet users, online and offline have a certain unity in Internet religious practice. The transmission or exchange of information is the most important mode of religious communication for users on the Internet. Of course, some websites use online gatherings to guide participants in deep breathing, meditation, and other behaviors to make cyberspace sacred, and correspondingly bring the elements of participation to offline real life.

\subsubsection{The attitude of the clergy towards Internet preaching has a positive impact on the believers}

Correlation testing shows that the highest correlation coefficient between Christian clergy's attitudes toward the Internet and the main problem items of believers' online religious activities is 0.469 , and the lowest is 0.231 . As the spokesperson of God, the clergy directly influence the believers' cognition, understanding, and attitude towards religious functions, communication channels, communication forms, and processes in social changes. The authority of religious network communication is mainly passed on to believers through the teaching staff. The survey shows that the online religious activities of the believers and their perceptions and attitudes towards online preaching are related to the clergy's recognition of the authoritative and functional online propaganda.

\subsubsection{Related to believers' perception of their own role in online education promotion}

Believers' attitudes toward online missions directly affect their missionary behavior. The analysis found that $57 \%$ of the respondents held a positive attitude towards the role of Internet promotion, and only $10.7 \%$ held a negative attitude. It is foreseeable that the believers' high degree of recognition of the role of online education promotion will inevitably be reflected in their behavior. Moreover, the related analysis also supports this judgment. These behaviors will manifest themselves as the believers' involvement in Internet preaching, as well as the involvement of religious organizations or churches in various religious activities organized through the Internet. The recognition of Internet promotion will also affect their evaluation of the Internet social capital 
possessed by religious organizations, religious sites (churches), and clergy.

Furthermore, $28.2 \%$ of the respondents agree that the role of popular believers in cyberspace is comparable to that of the clergy. This recognition of believers is, to a certain extent, a kind of power or even the grant of authority. This kind of grant, to a certain extent, is to give believers legitimacy in the dissemination of religion, and as a result, it will promote the enthusiasm and initiative of "popular" believers in the spread of the Internet. In other words, the spread of Christianity on the Internet has in fact increased the spreading power of believers.

In a sense, this means that as an empowering mechanism, network technology enables believers to enlarge their religious communication rights in cyberspace. This kind of enlargement may promote the entire dissemination structure of Christianity, dominated by the traditional top-down verticalization, and gradually turn to a state in which this structure mode is parallel to the bottom-up flat mode. In connection with this, it may push believers to enter a new stage in the development and evolution of faith-centered self-organization. To put it further, the authority structure of Christian organizations will undergo corresponding changes, which will promote adaptive changes in the internal structure of the church, the internal structure of the believers, and the relationship between the church and the believers.

Data analysis also found that there is a correlation between the respondents' behavior of obtaining religious information through the Internet and disseminating information. Specifically, the correlation coefficient between "Do you often learn about this religion through the Internet" and "Do you often communicate with friends online to learn the "Bible" experience is 0.479 , and it makes sense at a significance level of 0.01.Therefore, we can say that believers who often obtain knowledge and information about their religion through the Internet will often spread religious knowledge or information through the Internet, as the two sides of Internet communication, and the two promote each other.

\section{CONCLUSION}

Through the above-mentioned logical analysis of the current status, characteristics, and influencing factors of Christian believers' online religious communication behavior, we have reason to believe that the Internet of religion has changed traditional Christian religious practice to a certain extent. This change has an impact on the actual religion. The influence of the organization is structural, and it is both quantitative and qualitative in terms of elements and relationships. At the element level, the virtual space and the various elements derived from it have changed the structure of the original religious organization; at the relationship level, it not only reflects the changes in the relationship between believers and religious organizations, churches, and clergy but also reflects To change the relationship between believers and believers, the former changes the vertical power structure within the original organizational framework, while the latter changes the horizontal interaction between believers in the organization and may increase the cohesion of the organization. The changes in these relationships are not only the reconstruction of power but also the game of social capital. Faced with such changes, religious organizations, churches, and clergy will all have to make adjustments, and this adjustment will again have an impact on Internet communication. As far as religious management is concerned, dealing with the abovementioned changes brought about by the spread of online religion is the focus.

\section{ACKNOWLEDGMENTS}

This article is one of the phased results of the 2011 National Social Science Fund Western Project "Religious Organizations' Network Communication and Normative Research" (11XZJ025). The project data collection period is from 2014 to 2017; the central university's basic scientific research fund special fund project "City Research on the Community Dimension of Ethnic Minority Social Integration" (2019SYB75)

\section{REFERENCES}

[1] Campbell, H. (2005) Exploring Religious Community Online: We are one in the Network. Peter Lang, pp. 181-187.

[2] Campbell, H. (2015). Digital religion: understanding religious practice in new media worlds. International Journal of Public Theology, 9(2), 249-250.

[3] Dawson L. (2005) The Mediation of Religious Experience in Cyberspace, in M. Hojsgaard \& $\mathrm{M}$. Warburg (Eds.).Religion and cyberspace London, New York: Routledge, pp. 15-37. 